\title{
Indications of combined vitamin $K$ antagonists and aspirin therapy
}

\author{
A. Loualidi · S. H. J. Bredie · M. C. H. Janssen
}

Published online: 31 May 2008

(C) The Author(s) 2008

\begin{abstract}
Based on their mode of action, it is reasonable to expect that the combination therapy of aspirin and a vitamin $\mathrm{K}$ antagonist (VKA) may be more beneficial in preventing (athero) thrombotic complications in high-risk patients for cardiovascular events. However, there is no consensus about additional aspirin use in the most common indications for VKA or the use of VKAs to be added to the most common aspirin indications. The variation in clinical outcomes and bleeding complications suggests that extrapolating from one indication to another may not be appropriate. So far, decisions about the combined use of aspirin and VKA are individualized in the absence of adequate data. Only in patients with mechanical heart valves the benefits and safety of combining aspirin with VKA therapy seems obvious. In patients with peripheral artery disease no beneficial effect was noted for the combination therapy, perhaps with an exception of those with graft failure. For all other clinical situations, this is unclear and should be avoided.
\end{abstract}

Keywords: Antiplatelet therapy - Anticoagulant therapy · Vitamin K antagonists - Combination therapy ·

Atherosclerosis

\footnotetext{
A. Loualidi $(\bowtie)$ · S. H. J. Bredie · M. C. H. Janssen

Department of General Internal Medicine (463), Radboud

University Nijmegen Medical Centre, P.O. Box 9101,

HB 6500 Nijmegen, The Netherlands

e-mail: a.loualidi@aig.umcn.nl

S. H. J. Bredie

e-mail: s.bredie@aig.umcn.nl

M. C. H. Janssen

e-mail: m.janssen@aig.umcn.nl
}

\section{Introduction}

Platelets anti-aggregation drugs reduce cardiovascular events in nearly all groups of patients with clinical manifestations of atherosclerosis, including coronary artery, cerebrovascular and peripheral artery disease $[1,2]$. However, the cardiovascular risk remains elevated even if patients are on optimal secondary preventive treatments [1]. On the other hand the use of vitamin $\mathrm{K}$ antagonists (VKAs) remains the most efficacious antithrombotic regimen for the primary and secondary prevention of cardioembolic stroke in high-risk patients with atrial fibrillation, prosthetic valves and for the prevention and treatment of venous thromboembolism. However, their safe use requires intensive dose monitoring.

The combination therapy of aspirin and VKAs is frequently considered in various clinical settings and is increasingly applied in high risk patients because of (a) the expected additional protection against coronary artery disease to stroke prevention among patients with atrial fibrillation who are exposed to a high risk for future coronary diseases, (b) additional further stroke-preventive efficacy to usual international normalized ratio (INR) targets for highrisk groups and (c) the supposed reduced risk of haemorrhage by using lower INR targets while preserving efficacy.

\section{Methods}

The purpose of this article is to discuss the efficacy and safety of the dual of aspirin and VKAs prescription in clinical settings of secondary prevention. We therefore performed a computerized search via PubMed/MedLine and the Cochrane database using the MeSH terminology. Keywords were: aspirin, anti platelet agent, warfarin, 
coumarin, anticoagulant, vitamin $\mathrm{K}$ antagonist, dual therapy, combination therapy, atrial fibrillation, myocardial ischemia, heart valve diseases, cerebrovascular disorders, peripheral artery disease, atherosclerosis and venous thromboembolism.

\section{Results}

Clinical settings with an indication for a VKA:

is adding aspirin beneficial?

\section{Atrial fibrillation}

The risk of stroke in people with atrial fibrillation $(\mathrm{AF})$ is $3-5 \%$ per year, although this may vary according to other risk factors evaluated by the $\mathrm{CHADS}_{2}$-score (a clinical prediction rule for estimating the risk of stroke in patients with AF) [3]. The risk of stroke in people with $\mathrm{AF}$ who have had a previous transient ischemic attack (TIA) may be as high as $12 \%$ per year. Anticoagulants have been proven to be more effective in prevention of ischemic stroke in people with AF than aspirin [4].

The current guideline recommends anticoagulation with a VKA in patients with persistent or paroxysmal $\mathrm{AF}$ at high risk of stroke (i.e., having any of the following features: prior ischemic stroke, transient ischemic attack, or systemic embolism, age $>75$ years, moderately or severely impaired left ventricular systolic function and/or congestive heart failure, history of hypertension, or diabetes mellitus, corresponding to $\mathrm{a} \mathrm{CHADS}_{2}$-score of 3 or more). In patients between age 65 and 75 years, in the absence of other risk factors, who are at intermediate risk of stroke (i.e. $\mathrm{CHADS}_{2}$-score $\leq 2$ ) antithrombotic therapy with either a VKA or aspirin is recommended. In patients with persistent AF or paroxysmal AF below the age of 65 years who have no other risk factors $\left(\mathrm{CHADS}_{2}\right.$-score $\left.=0\right)$, aspirin is recommended [5].

Although no additional benefit has been demonstrated from combining aspirin and a VKA for stroke prophylaxis in AF patients, concomitant conditions such us coronary artery disease (CAD), peripheral artery and cerebrovascular disease are indications for aspirin. However, there is insufficient evidence to justify the routine use of antiplatelet agents in addition to a VKA in these situations, primarily, because safety data of dual therapy are lacking: Table 1 shows the relative risk and the bleeding risk of the concomitant use of both aspirin and VKAs in patients with $\mathrm{AF}$ in different conducted studies. Lechat et al. found that there was no statistical difference between the groups for the primary endpoints, but haemorrhagic complications were significantly more frequent in the aspirin group [8]. Gullov et al. found in the AFASAK 2 trial that fixed-minidose warfarin and aspirin alone or in combination were

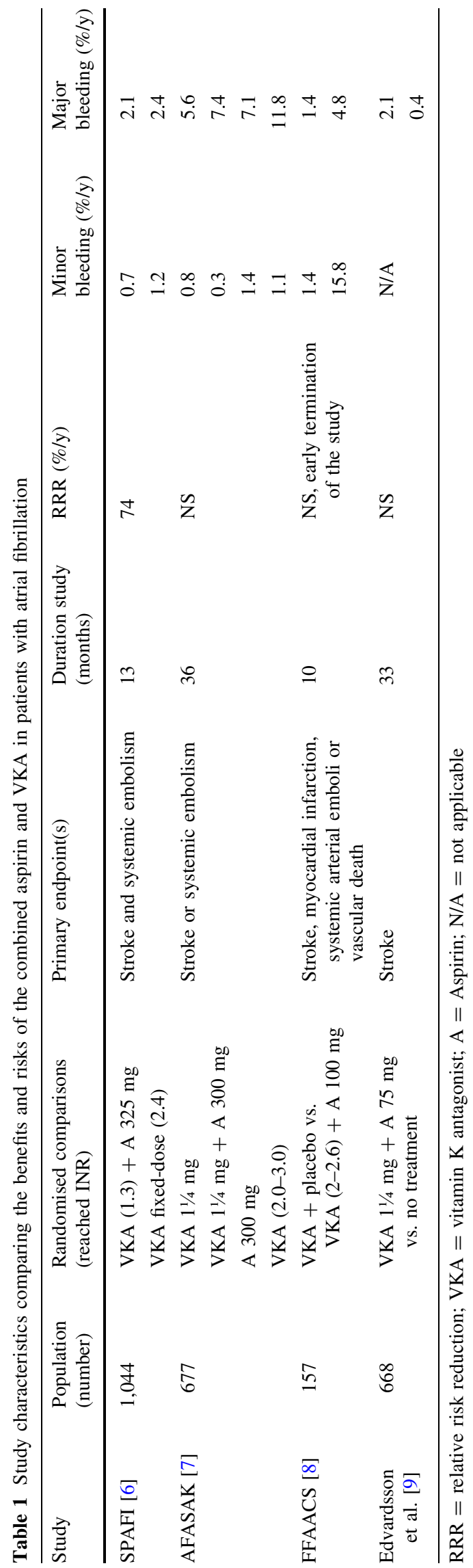


associated with both minor and major bleeding [7]. In a recent study with 3,566 patients with chronic $\mathrm{AF}$, receiving warfarin therapy targeted to achieve an INR of 2.0-3.0, patients who were receiving concomitant aspirin $(100 \mathrm{mg} /$ day) had a more than 2-fold increased risk for major bleeding [10].

The trial conducted by Edvardsson et al. [9] on the effect of low-dose warfarin and aspirin vs. no treatment on stroke in a medium-risk population with $\mathrm{AF}$ was inconclusive, but consistent with a small beneficial effect of the combination therapy for reduction of stroke and major vascular events. However this slight advantage was accompanied with significantly increased risk of bleeding.

In the SPAFI trial [6] low-intensity, fixed-dose warfarin plus aspirin was insufficient for stroke prevention in patients with non-valvular AF at high-risk for thromboembolism; adjusted-dose warfarin (target INR 2.0-3.0) reduced stroke in high-risk patients importantly. In these highly selected high-risk patients with $\mathrm{AF}$ major bleeding occurred at comparable rates with both treatments.

In conclusion none of the conducted studies demonstrated a benefit of the antiplatelet and VKAs therapy combination. This combination therapy provides no better prophylaxis against stroke than a VKA alone while mild and severe haemorrhagic complications are significantly more frequent.

\section{Valvular heart disease}

Patients with prosthetic heart valves are at increased risk for valve thrombosis and valve related thromboembolism [11-13]. Life-long oral anticoagulation is considered to be essential for the prevention of thromboembolic events after implantation of a mechanical heart valve. Nevertheless, thromboembolic events occur after mechanical valve replacement in approximately $2-4 \%$ of patients per year despite the use of a VKA [14]. The addition of antiplatelet drugs to VKAs has been suggested and used to minimize this risk. An important issue is the effectiveness and safety of this strategy.

In 2003 The Cochrane Collaboration has published a review on the use of antiplatelet therapy and VKA in patients with prosthetic heart valves [15]. The authors reported that, compared to anticoagulation alone, the addition of an antiplatelet agent reduced the risk of thromboembolic events (odds ratio 0.39 (95\% confidence interval (CI): $0.28-0.56 ; P<0.00001)$ ) and total mortality (odds ratio 0.55 (95\% CI: $0.40-0.77 ; P=0.0003$ )). The risk of major bleeding was increased when antiplatelet agents were added to VKAs (odds ratio 1.66 (95\% CI: $1.18-2.34 ; P=0.003)$ ). They concluded that adding antiplatelet therapy to a VKA decreases the risk of systemic embolism or death among patients with prosthetic heart valves while the risk of major bleeding is increased with antiplatelet therapy when added to a VKA.

The seventh ACCP conference on antithrombotic and thrombolytic therapy recommends the use of aspirin (75$100 \mathrm{mg} /$ day) for patients who have mechanical heart valves and additional risk factors such as $\mathrm{AF}$, myocardial infarction, left atrial enlargement, endocardial damage, and low ejection fraction and for patients with mechanical prosthetic heart valves who suffer from systemic embolism despite a therapeutic INR [16].

In two more recently published meta-analyses, it was definitely established that adding antiplatelet therapy, especially low-dose aspirin, to a VKA decreases the risk of systemic embolism or death among patients with prosthetic heart valves $[17,18]$. The risk of major bleeding is slightly increased when adding antiplatelet therapy. Nonetheless, the risk of bleeding appears to be diminished with the lower doses of aspirin used in the more recent trials, resulting in a favourable risk-to-benefit profile. Older trials (Table 2) noted a significant increase in bleeding, particularly when high doses of aspirin were used $(500 \mathrm{mg} /$ day or more) in combination with high-intensity of a VKA.

In conclusion, the shown data demonstrate that the benefits of the combination of a VKA and aspirin outweighs the bleeding risks and that adding antiplatelet therapy to a VKA is more effective than anticoagulant therapy alone.

\section{Venous thromboembolism}

We found no trials evaluating the effects of Aspirin on top of a VKA indicated for venous thrombosis. Prospective randomised controlled clinical trials are therefore needed to disclose this clinical issue.

Clinical settings in which aspirin is indicated: is adding a VKA beneficial?

\section{Non-cardioembolic stroke}

Patients with limited cerebral ischemia of arterial origin are at risk of serious vascular events (4-11\% annually) [26, 27]. Aspirin is generally recommended in patients with previous ischemic stroke or transient ischemic attack to reduce the risk of recurrence. In general, it reduces the incidence of major vascular events up to $20 \%$ [26-28].

VKAs are commonly recommended for the prevention of recurrent stroke in patients with $\mathrm{AF}$, but to date it has no role in the prevention of non-cardioembolic ischemic stroke. No trials were found comparing the combination of aspirin and VKAs in combination to aspirin alone in the prevention of stroke of presumed arterial origin. The explanation for this may be that previous trials on VKA monotherapy in cerebrovascular disease were not more 


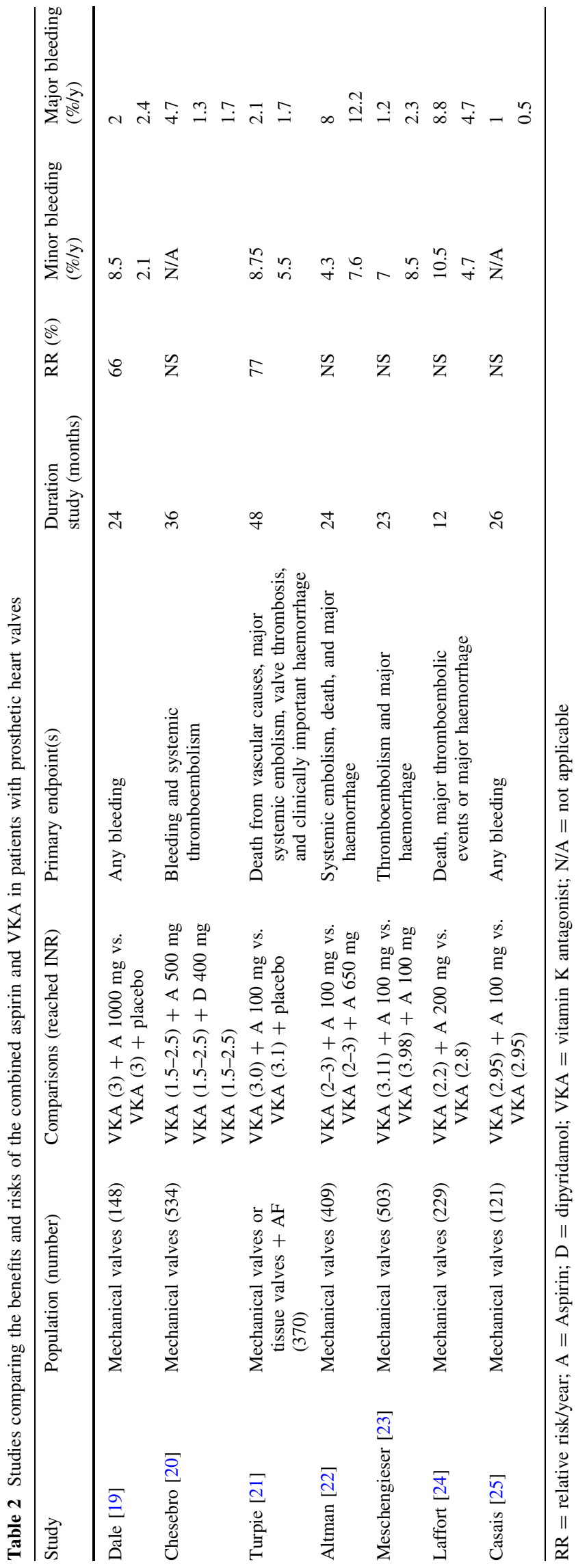

efficacious than aspirin monotherapy, but were associated with higher bleeding rates. In an update of a Cochrane review in 2006, Algra et al. compared the efficacy and safety of VKAs and antiplatelet therapy in the secondary prevention of vascular events after cerebral ischemia of presumed arterial origin [29]. They found insufficient evidence to justify the routine use of medium intensity oral anticoagulants (INR 2.0-3.6); more intense anticoagulation (INR 3.0-4.5) was not safe because it yielded more major bleeding complications and should therefore not be used in this clinical setting. Even in the lowest intensity INR range, addition of warfarin had no benefit above aspirin alone. The WARSS study that compared the effect of aspirin $(325 \mathrm{mg})$ to that of warfarin at a dose adjusted to produce an INR of 1.4-2.8 on recurrence of ischemic stroke or death from any cause within 2 years. This study showed no significant differences between the two modalities in any of the outcomes measured [30].

In patients with non-cardioembolic stroke, oral anticoagulants are no more effective than aspirin alone but cause more bleeding. However data on the safety and effectiveness of the dual therapy are lacking.

\section{Myocardial infarction}

Patients with a history of myocardial infarction are at increased risk for recurrent infarction, stroke and death $[31,32]$. Although aspirin provides benefit preventing recurrent myocardial infarction, the rates of recurrent vascular events in patients with coronary artery disease remains high [26]. There is evidence that a marked thrombin generation persists for months after acute cardiac events. Such a persistent stimulus to thrombosis even in the presence of aspirin [33], may indicate a role for anticoagulation therapy in this condition. This hypothesis has led to the conduction of several trials testing the combination therapy of aspirin and VKAs at varying intensities. Although some studies have shown that addition of VKAs to aspirin decreases subsequent risk for cardiovascular events, most studies did not (Table 3). Because of the conflicting results of the trails so far, different meta-analysis have been conducted in an attempt to clarify this issue: Anand and Yusuf [2, 43] suggested that high-intensity oral anticoagulation (INR $>2.8$ ) significantly reduced cardiovascular complications but increased bleeding rates compared with controls while the combination of moderate-intensity oral anticoagulation and aspirin was more effective and equally safe as aspirin alone. Low-intensity oral anticoagulation (INR $<2.0$ ) in combination with aspirin did not reduce cardiovascular complications and increased bleeding compared to aspirin alone. The results of the meta-analysis guided by Rothberg et al. bolsters the finding that after an acute coronary 


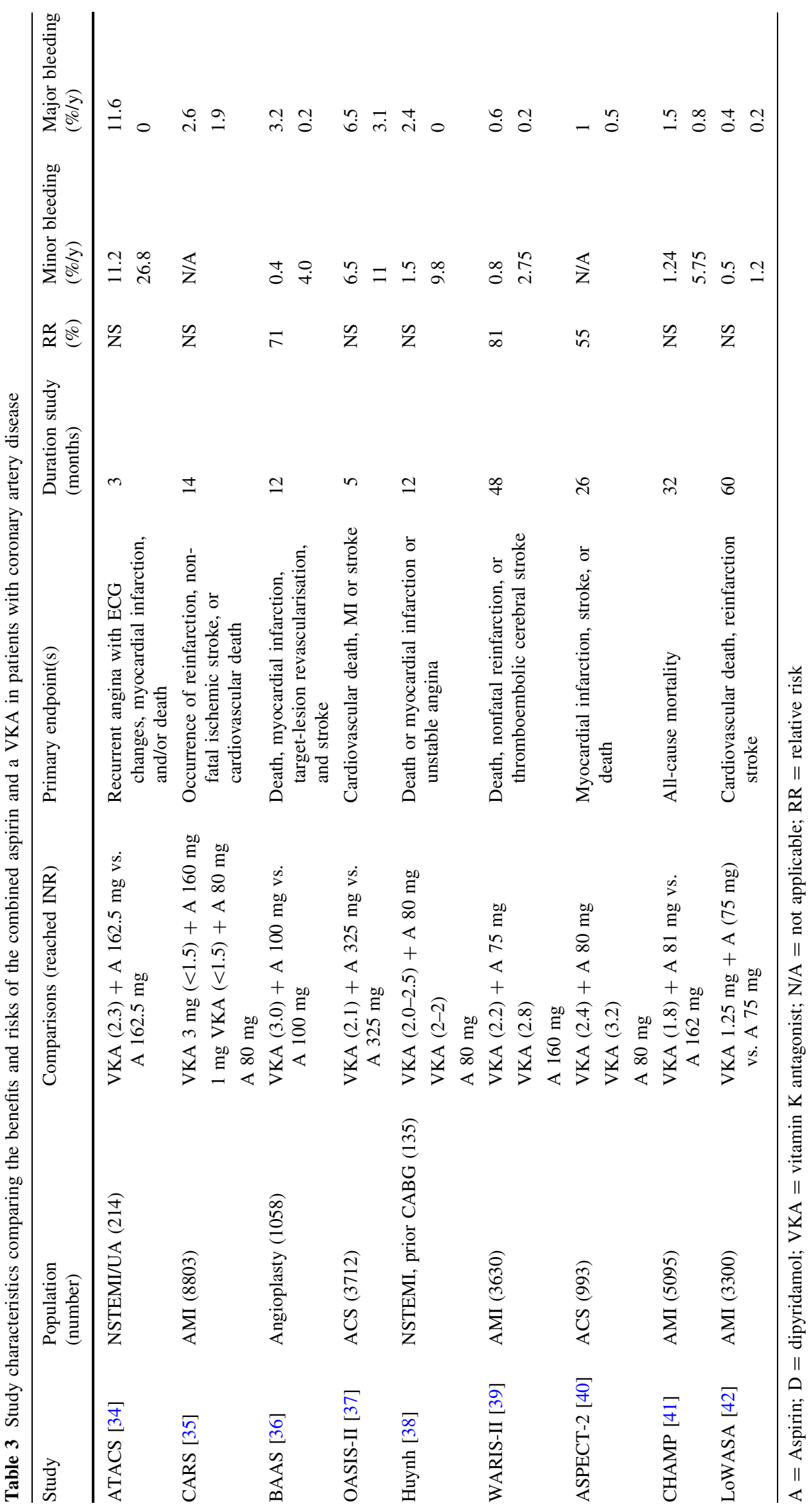


syndrome, VKAs plus aspirin decreases the rate of myocardial infarction or stroke more than aspirin alone [44]. Although the probability of major bleeding is also increased, the benefits would far outweigh the bleeding risks for many patients. On the other hand, the more recent performed meta-analysis by Dentali et al. has shown no benefits of combining aspirin and VKAs in patients with coronary artery disease: there was no difference in allcause mortality with either treatment while the risk for major bleeding was higher in the combination group [17].

The data in Table 3 show that adding VKAs to aspirin in this patient category reduces ischemic events but increases the rates of bleeding complications.

\section{Peripheral artery disease (PAD)}

Aspirin therapy, while having no effect on walking distance or symptom status, seems to modify the clinical course of PAD. Large randomised trials have shown that aspirin monotherapy delays the progression of established $\mathrm{PAD}$, as assessed by serial angiography, and decreases the need for surgical revascularisation [45, 46]. Among patients with $\mathrm{AF}$ and claudicatio intermittens, in whom there is a particular risk of acute embolic lower limb ischemia and stroke, randomised control trials and metaanalyses have clearly indicated that anticoagulation with a VKA (target INR 2.5-3.5) is superior to aspirin [47].

Previous data on dual therapy with aspirin and VKAs in patients with PAD and sinus rhythm are conflicting, small, heterogeneous and non-consistent. Many of these studies focused on peripheral artery patency after vascular reconstruction and were not designed to assess the potential benefit of a VKA to reduce future cardiovascular outcomes [36, 48-53]. As the rate of CV events is 5 times higher in patients with PAD compared to patients without PAD and moderate intensity VKA is effective in reducing $\mathrm{CV}$ events in patients with $\mathrm{CAD}$, there is a strong rationale for testing the efficacy of long-term moderate intensity VKA (target INR between 2 and 3 ) in addition to antiplatelet therapy to prevent major vascular events in patients with PAD. The conducted WAVE (the Warfarin and Antiplatelet Vascular Evaluation)-trial [54], a large, international, randomised clinical trial of patients at a high risk for vascular diseases was designed to determine if moderate VKAs anticoagulation (INR 2-3), in addition to antiplatelet therapy is superior to antiplatelet therapy alone. The conclusion was that a VKA (targeting an INR range of 2-3) added to antiplatelet therapy did not lower the rate of cardiovascular events or death, but causes a 3.5-fold increase in severe bleeding complications including cerebral haemorrhage. Life-threatening bleeding was seen in $4.0 \%$ on the combination therapy vs. $1.2 \%$ with aspirin alone $(P<0.001)$, effectively ruling out this dual approach in PAD (Table 4).

\section{Discussion}

There is no consensus about combining VKAs and aspirin in the most common indications for the use of anticoagulants and aspirin. Based on their mode of action, it is reasonable to expect that the combination therapy of aspirin and a VKA may be more beneficial in preventing (athero) thrombotic complications for cardiovascular events. Unfortunately, also bleeding complications may overweigh the potential advantage, so far the variations in outcomes suggest that extrapolating from one indication to another may not be appropriate.

\section{Atrial fibrillation}

The rationale for a dual therapy in $\mathrm{AF}$ is to reduce the risk of bleeding in patients with AF by using low dose of VKAs added to aspirin, to give additional stroke-preventive efficacy to usual anticoagulation in patients considered to be at high risk of thrombotic complications and the supposed additional protection against coronary artery disease to stroke prevention among patients with AF who are exposed to a high risk for future coronary diseases. However, there is insufficient evidence found to justify the concomitant use of aspirin and a VKA: none of the conducted studies demonstrated a benefit of the combination therapy. Therefore clinicians should be aware of the risks of combining aspirin and VKAs especially in our (ageing) population where the co-prevalence of atherosclerosis and AF escalates. Aspirin on top of a VKA provides no better prophylaxis against stroke than a VKA alone while haemorrhagic complications are significantly more frequent.

Table 4 Study characteristics comparing the benefits and risks of the combined aspirin and VKAs in patients with peripheral artery disease

\begin{tabular}{|c|c|c|c|c|c|c|c|}
\hline Study & $\begin{array}{l}\text { Population } \\
\text { (number) }\end{array}$ & $\begin{array}{l}\text { Comparisons } \\
\text { (reached INR) }\end{array}$ & Primary endpoint(s) & $\begin{array}{l}\text { Duration study } \\
\text { (months) }\end{array}$ & $\begin{array}{l}\mathrm{RR} \\
(\%)\end{array}$ & $\begin{array}{l}\text { Minor } \\
\text { bleeding }\end{array}$ & Major bleeding \\
\hline WAVE [54] & PAD (2161) & VKA $(2-3)+$ A vs. A & $\begin{array}{l}\text { Myocardial infarction, } \\
\text { stroke, or death from } \\
\text { cardiovascular causes }\end{array}$ & 42 & 92 & $\begin{array}{l}0.8 \% / y \\
0.3 \% / y\end{array}$ & $\begin{array}{l}\mathrm{VKA}+\mathrm{A}(1.1 \% / \mathrm{y}) \\
\mathrm{A}(0.3 \% / \mathrm{y})\end{array}$ \\
\hline
\end{tabular}

$\mathrm{RR}=$ relative risk 


\section{Prosthetic valves}

In case of prosthetic valves we can state that at present-day all the data analysing the combined use of aspirin and a VKA show a significantly lower risk for thromboembolism and that the benefits of the combination of a VKA and aspirin outweighs the bleeding risks and should be particularly useful in patients with established cardiovascular diseases, additional risk factors or recurrent embolism despite a therapeutic INR. In fact, mechanical heart valves remain the only clinical entity for which robust evidence is demonstrated in randomised trials that adding antiplatelet therapy to anticoagulant therapy is more effective than anticoagulant therapy alone.

\section{Venous thromboembolism}

We found no study evaluating the effects of adding aspirin to a VKA indicated for venous thromboembolism in case of concomitant aspirin indication. It is reasonable, based on their mode of action, to expect that the combination therapy of aspirin and a VKA may be more beneficial in preventing (athero) thrombotic complications in patients with venous thromboembolism. The onset of a venous thromboembolic event in patients who already take aspirin as a prophylaxis because they are at moderate to high risk for thromboembolic events, leads to the initiation of a VKA. At the time of VKA initiation, aspirin should be stopped because of the estimated higher risk of bleeding and the lack of evidence to support the combined use of aspirin and VKA in this patient category.

\section{Non-cardioembolic stroke}

Because of the lack of data from well-designed randomised trials assessing the combined therapy in patients with noncardioembolic stroke and the finding that VKAs as monotherapy are not more efficacious than aspirin, antiplatelet agents remains nowadays the cornerstone of secondary prevention. VKAs are commonly recommended for the prevention of recurrent stroke in patients with $\mathrm{AF}$, but it has a lesser or no role in the prevention of noncardioembolic ischemic stroke. Given the risk/benefit ratio, costs of monitoring therapy, and difficulty in maintaining a therapeutic INR in a community setting, antiplatelet agents are preferred over VKAs for prevention of recurrent ischemic stroke. However VKAs should be considered in patients who cannot tolerate antiplatelet agents [55, 56].

\section{Coronary artery disease}

Conflicting results are found on this issue: in some studies clear reductions in total mortality, myocardial infarction, and stroke occurred among patients treated with VKAs at high intensity, although this therapy was also associated with a significant increase in major bleeding. Conversely, low-intensity anticoagulation in the presence of aspirin does not confer any benefit over aspirin alone but still increases major bleeding episodes. Moderate-intensity anticoagulation reduced recurrent ischemic events and seems to be more effective than aspirin alone and to be relatively safe. This combination should be considered for high-risk patients with CAD, including those who suffer a CV event while receiving aspirin monotherapy. The potential benefits of VKA therapy in reducing serious clinical events should be weighed against life-threatening bleedings.

In a recent review Eijkelboom and Hirsh found that adding VKA to aspirin reduces recurrent ischemic events but does not reduce death and increases major bleeding [57]. This increase in bleeding appears to be outweighed by the reduction in recurrent myocardial infarction but the potential for an increase in intracranial bleeding with the combination of a VKA and aspirin is concerning.

\section{Peripheral artery disease}

Aspirin therapy is effective in preventing cardiovascular events and death in patients with peripheral artery disease [1]. No beneficial effect was noted for the combination therapy of aspirin and VKA. In the WAVE trial, adding a VKA to aspirin did not improve the clinical outcomes: the primary outcome, a composite of MI, stroke or death was not significantly different in the two groups but the rates of bleedings and life-threatening bleeding was significantly increased among patients treated with the combination of a VKA and antiplatelet therapy.

However, this dual approach could be beneficial in specific patient groups such as peripheral arterial reconstructive surgery, recurrent graft failure and in cases of limb salvage. Many randomised trials in patients with various vascular disorders have studied the efficacy of aspirin in the prevention of ischemic events. The Antiplatelet Trialists' Collaboration showed a beneficial effect of aspirin therapy with no clear differences between types of arterial disease. The efficacy of long-term treatment with aspirin in patient's who undergo infrainguinal bypass surgery, however, has been studied in only a few randomised trials [58-62]. The BOA (The Dutch Bypass Oral Anticoagulants or Aspirin) trial showed that VKAs were better for the prevention of infra-inguinal-vein-graft and for lowering the rate of ischemic events. Aspirin was better for the prevention of non-venous graft occlusion, and was associated with fewer bleeding episodes [36]. What the efficacy and safety of the combination therapy of aspirin and VKAs in such specific subgroups with peripheral artery diseases is not clear. 


\section{Conclusion}

This overview makes clear that only for patients with mechanical heart valve the benefits and safety of combining aspirin with a VKA are clear. For patients with peripheral artery disease no beneficial effect was noted for the dual therapy. For other medical settings, there are no adequate data to guide this common clinical conclusion.

Open Access This article is distributed under the terms of the Creative Commons Attribution Noncommercial License which permits any noncommercial use, distribution, and reproduction in any medium, provided the original author(s) and source are credited.

\section{References}

1. Antithrombotic Trialists' Collaboration (2002) Collaborative meta-analysis of randomised trials of antiplatelet therapy for prevention of death, myocardial infarction, and stroke in high-risk patients. Br Med J 324(7329):71-86

2. Anand SS, Yusuf S (1999) Oral anticoagulants in patients with coronary artery disease: a meta analysis. JAMA 282(21):2058-2067

3. Flemming KD, Brown RD Jr (2004) Secondary prevention strategies in ischemic stroke: identification and optimal management of modifiable risk factors. Mayo Clin Proc 79(10):1330-1340

4. Hart RG, Benavaente O, McBride R et al (1999) Antithrombotic therapy to prevent stroke in AF: a meta-analysis. Ann Intern Med 131(7):492-501

5. Singer DE, Albers GW, Dalen JE, Go AS, Halperin JL, Manning WJ (2004) Antithrombotic therapy in atrial fibrillation: the seventh ACCP conference on antithrombotic and thrombolytic therapy. Chest 126(3 suppl):429S-456S

6. Stroke Prevention in Atrial Fibrillation Investigators (1996) Adjusted-dose warfarin versus low-intensity, fixed-dose warfarin plus aspirin for high-risk patients with atrial fibrillation: stroke prevention in atrial fibrillation III randomised clinical trial. Lancet 348(9028):633-638

7. Gullov AL, Koefoed BG, Peterson P (1999) Bleeding during warfarin and aspirin therapy, in patients with atrial fibrillation, The AFASAK 2 study. Arch Intern Med 159(12):1322-1328

8. Lechat P, Lardoux H, Mallet A, Sanchez P, Derumeaux G, Lecompte $\mathrm{T}$ et al (2001) Anticoagulant (fluindione)-aspirin combination in patients with high-risk atrial fibrillation a randomised trial (Fluindione, Fibrillation Auriculaire, Aspirin et Contraste Spontané; FFAACS). Cerebrovasc Dis 12(3):245-252

9. Edvardsson N, Juul-Moller SJ et al (2003) Effects of low-dose warfarin and aspirin versus no treatment on stroke in a mediumrisk patient population with atrial fibrillation. J Intern Med 254(1):95-101

10. Douketis JD, Arneklev K, Goldhaber SZ, Spandorfer J, Halperin F, Horrow J (2006) Comparison of bleeding in patients with nonvalvular atrial fibrillation treated with ximelagatran or warfarin. Arch Intern Med 166(8):853-859

11. Michel PL, Acar J (1998) Prothèses valvulaires mécaniques et biologiques et traitements antithrombotiques. In: Samama MM, Acar J (eds) Traitement Antithrombotique, Masson Edit, 3rd edn. Paris, pp 143-175

12. Acar J, Michel PL, Iung B (1997) Les accidents thromboemboliques des prothèses valvulaires: incidence, prévention et traitement en 1997. Sang Thromb Vaiss 9(3):172-178

13. Aupart M, Diemont F, Babuty S et al (1997) Résultats intermédiaires avec la prothèse valvulaire à ailettes CarboMedics. Arch Mal Coeur 9(4):457-462
14. Cannegieter SC, Rosendaal FR, Briet E (1994) Thromboembolic and bleeding complications in patients with mechanical heart valve prostheses. Circulation 89(2):635-641

15. Little SH, Massel DR (2003) Antiplatelet and anticoagulation for patients with prosthetic heart valves. The Cochrane Database of Systematic Reviews Issue (4):CD003464

16. Salem DN, Stein PD, Al-Ahmad A, Bussey HI, Horstkotte D, Miller N, Pauker SG (2004) Antithrombotic therapy in valvular heart disease-native and prosthetic: the seventh ACCP conference on antithrombotic and thrombolytic therapy. Chest $126(3$ suppl):457S-482S

17. Dentali F, Douketis JD, Lim W, Crowther M (2007) Combined aspirin-oral anticoagulant therapy compared with oral anticoagulant therapy alone among patients at risk for cardiovascular disease: a meta-analysis of randomized trials. Arch Intern Med 167(2):117-124

18. Massel D, Little SH (2001) Risks and benefits of adding antiplatelet therapy to warfarin among patients with prosthetic heart valves: a meta-analysis. J Am Coll Cardiol 37(2):569-578

19. Dale J, Myhre E, Loew D (1980) Bleeding during acetylsalicylic acid and anticoagulant therapy in patients with reduced platelet reactivity after aortic valve replacement. Am Heart J 99:746-752

20. Chesebro JH, Fuster V, Elveback LR, McGoon DC, Pluth JR, Puga FJ, Wallace RB, Danielson GK, Orszulak TA, Piehler JM, Schaff HV (1983) Trial of combined warfarin plus dipyridamole or aspirin therapy in prosthetic heart valve replacement: danger of aspirin compared with dipyridamole. Am J Cardiol 51(9):15371541

21. Turpie AG, Gent M, Laupacis A, Latour Y, Gunstensen J, Basile F, Klimek M, Hirsh J (1993) A comparison of aspirin with placebo in patients treated with warfarin after heart-valve replacement. N Engl J Med 329(8):524-529

22. Altman R, Rouvier J, Gurfinkel E et al (1996) Comparison of high-dose with low-dose aspirin in patients with mechanical heart valve replacement treated with oral anticoagulant. Circulation 94:2113-2116

23. Meschengieser SS, Fondevilla C, Santarelli MT et al (1997) Low intensity oral anticoagulation plus low dose aspirin versus highintensity oral anticoagulation alone: a randomized trial in patients with mechanical prosthetic heart valves. J Thorac Cardiovasc Surg 113:910-916

24. Laffort P, Roudaut R, Roques X, Lafitte S, Deville C, Bonnet J, Baudet E (2000) Early and long-term (one-year) effects of the association of aspirin and oral anticoagulant on thrombi and morbidity after replacement of the mitral valve with the St. Jude medical prosthesis: a clinical and transesophageal echocardiographic study. J Am Coll Cardiol 35:739-746

25. Casais P, Meschengieser SS, Sanchez Luceros AG, Bermejo EI, Lazzari MA (2002) Effect of low-dose aspirin on the international normalized ratio variability in patients with mechanical heart valve prostheses. Pathophysiol Haemost Thromb 32:155-157

26. Antiplatelet Trialists' Collaboration (1994) Collaborative overview of randomised trials of antiplatelet therapy, I: prevention of death, myocardial infarction, and stroke by prolonged antiplatelet therapy in various categories of patients. Br Med J 308(6921):81106

27. Algra A, van Gijn J (1996) Aspirin at any dose above $30 \mathrm{mg}$ offers only modest protection after cerebral ischaemia. J Neurol Neurosurg Psychiatry 60(2):197-199

28. Algra A, van Gijn J (1999) Cumulative meta-analysis of aspirin efficacy after cerebral ischaemia of arterial origin. J Neurol Neurosurg Psychiatry 66(2):255; Letter

29. Algra A, De Schryver ELLM, van Gijn J, Kappelle LJ, Koudstaal PJ (2003) Oral anticoagulants versus antiplatelet therapy for preventing further vascular events after transient ischemic attack or minor stroke of presumed arterial origin. Stroke 34(1):234-235 
30. WARSS Investigators (2006) Comparison of warfarin versus aspirin for the prevention of recurrent stroke or death: subgroup analyses from the Warfarin-Aspirin Recurrent Stroke Study. Cerebrovasc Dis 22(1):4-12

31. Moss AJ, Benhorin J (1990) Prognosis and management after a first myocardial infarction. N Engl J Med 322(11):743-753

32. Kornowski R, Goldbourt U, Zion M, Mandelzweig L, Kaplinsky E, Levo Y et al (1993) Predictors and long-term prognostic significance of recurrent infarction in the year after a first myocardial infarction. SPRINT Study Group. Am J Cardiol 72(12):883-888

33. Merlini PA, Bauer KA, Oltrona L, Ardissino D, Cattaneo M, Belli C, Mannucci PM, Rosenberg RD (1994) Persistent activation of coagulation mechanism in unstable angina and myocardial infarction. Circulation 90(1):61-68

34. Cohen M, Adams PC, Parry G, Xiong J, Chamberlain D, Wieczorek I, Fox KA, Chesebro JH, Strain J, Keller C et al (1994) Combination antithrombotic therapy in unstable rest angina and non-Q-wave infarction in nonprior aspirin users. Primary end points analysis from the ATACS trial. Antithrombotic Therapy in Acute Coronary Syndromes Research Group. Circulation 89(1):81-88

35. CARS Investigators (1997) Randomized double blind trial of fixed low-dose warfarin with aspirin after myocardial infarction. Lancet 350:389-396

36. Anonymous (2000) Efficacy of oral anticoagulants compared with aspirin after infrainguinal bypass surgery (The Dutch Bypass Oral Anticoagulants or Aspirin Study): a randomised trial. Lancet 355(9201):346-351

37. The Organization to Assess Strategies for Ischemic Syndromes (OASIS) Investigators (2001) Effects of long-term, moderateintensity oral anticoagulation in addition to aspirin in unstable angina. J Am Coll Cardiol 37:475-484

38. Huynh T, Théroux P, Bogaty P, Nasmith J, Solymoss S (2001) Aspirin, warfarin, or the combination for secondary prevention of coronary events in patients with acute coronary syndromes and prior coronary artery bypass surgery. Circulation 103(25):30693074

39. Hurlen M, Abdelnoor M, Smith P, Erikssen J, Arnesen H (2002) Warfarin, aspirin, or both after myocardial infarction. N Engl $\mathrm{J}$ Med 347:969-974

40. van Es RF, Jonker JJ, Verheugt FW, Deckers JW, Grobbee DE (2002) Antithrombotics in the Secondary Prevention of Events in Coronary Thrombosis-2 (ASPECT-2) Research Group. Aspirin and coumadin after acute coronary syndromes (the ASPECT-2 study): a randomised controlled trial. Lancet 360(9327):109-113

41. Fiore LD, Ezekowitz MD, Brophy MT et al (2002) Department of Veterans Affairs Cooperative Studies Program Clinical Trial comparing combined warfarin and aspirin with aspirin alone in survivors of acute myocardial infarction: primary results of the CHAMP study. Circulation 105:557-563

42. Herlitza J, Holmb J, Petersonc M, Karlsona BW, Evandera MH, Erhardtb L, for the LoWASA study group (2004) Effect of fixed low-dose warfarin added to aspirin in the long term after acute myocardial infarction the LoWASA study. Eur Heart J 25:232239

43. Anand S, Yusuf S (2003) Oral anticoagulants in patients with coronary artery disease. J Am Coll Cardiol 41(4 suppl):62S-69S

44. Rothberg MB, Celestin C, Fiore LD, Lawler E, Cook JR (2005) Warfarin plus aspirin after myocardial infarction or the acute coronary syndrome: meta-analysis with estimates of risk and benefit. Ann Intern Med 143(4):241-250

45. Goldhaber SZ, Manson JE, Stampfer MJ, LaMotte F, Rosner B, Buring JE, Hennekens CH (1992) Low-dose aspirin and subsequent peripheral arterial surgery in the Physician's Health Study. Lancet 340(8812):143-145

46. Hirsh J, Dalen JE, Fuster V, Harker LB, Salzman EW (1992) Aspirin and other anti-platelet drugs: the relationship between dose, effectiveness, and side effects. Chest 102 (4 suppl):327S$336 \mathrm{~S}$

47. Stroke Prevention in Atrial Fibrillation Investigators (1994) Warfarin versus aspirin for prevention of thromboembolism in atrial fibrillation: stroke prevention in Atrial Fibrillation II study. Lancet 343(8899):687-691

48. Kretschmer G, Herbst F, Prager M, Sautner T, Wenzl E, Berlakovich GA, Zekert F, Marosi L, Schemper M (1992) A decade of oral anticoagulant treatment to maintain autologous vein grafts for femoropopliteal atherosclerosis. Arch Surg 127(9):1112-1115

49. Arfvidsson B, Lundgren F, Drott C et al (1990) Influence of coumarin treatment on patency and limb salvage after peripheral arterial reconstructive surgery. Am J Surg 159(6):556-560

50. de Smit P, van Urk H (1992) Dutch oral anticoagulation trial. Act Chir Austr 24(1):5-7

51. Sarac TP, Huber TS, Back MR et al (1998) Warfarin improves the outcome of infrainguinal vein bypass grafting at high-risk for failure. J Vasc Surg 28(3):446-457

52. Johnson WC, Williford WO (2002) Benefits, morbidity, and mortality associated with long-term administration of oral anticoagulant therapy to patients with peripheral arterial bypass procedures: a prospective randomised study. J Vasc Surg 35(3):413-421

53. Chesney CM, Elam MB, Herd JA, Davis KB, Garg R, Hunninghake, Kennedy JW, Applegate WB (2000) Effect of niacin, warfarin, and antioxidant therapy on coagulation parameters in patients with peripheral arterial disease in the arterial disease multiple intervention trial (ADMIT). Am Heart J 140(4):631-636

54. The Warfarin Antiplatelet Vascular Evaluation Trial Investigators (2007) Oral anticoagulant and antiplatelet therapy and peripheral arterial disease. N Engl J Med 357(3):217-227

55. Sacco RL, Adams R, Albers G, Alberts MJ, Benavente O, Furie K et al (2006) Guidelines for prevention of stroke in patients with ischemic stroke or transient ischemic attack. Stroke 37(2):577617

56. Albers GW, Amarenco P, Easton JD, Sacco RL, Teal P (2004) Antithrombotic and thrombolytic therapy for ischemic stroke: the seventh ACCP conference on antithrombotic and thrombolytic therapy. Chest 126 (3 suppl):483S-512S

57. Eikelboom JW, Hirsh L (2007) Combined antiplatelet and anticoagulant therapy: clinical benefits and risks. J Thromb Haemost 5(1 Suppl):255-263

58. Donaldson DR, Salter MC, Kester RC et al (1985) The influence of platelet inhibition on the patency of femoro-popliteal Dacron bypass grafts. J Vasc Surg 19(4)224-230

59. Goldman MD, McCollum CN (1984) A prospective randomised study to examine the effect of aspirin plus dipyridamole on the patency of prosthetic femoro-popliteal grafts. J Vasc Surg 18(4): 217-221

60. Green RM, Roedersheimer LR, DeWeese JA (1982) Effects of aspirin and dipyridamole on expanded polytetrafluoroethylene graft patency. Surgery 92(6):1016-1026

61. Kohler TR, Kaufman JL, Kacoyanis GP et al (1984) Effect of aspirin and dipyridamole on the patency of lower extremity bypass grafts. Surgery 96(3):462-466

62. McCollum C, Alexander C, Kenchington G, Franks PJ, Greenhalgh RM (1991) Anti-platelet drugs in femoropopliteal vein bypasses: a multicentre trial. J Vasc Surg 13(1):150-162 